\section{Abortamento provocado na adolescência sob a perspectiva bioética}

\section{Abortion among adolescents: a bioethical approach}

José Humberto Belmino Chaves 1

Leo Pessini 2

Antônio Fernando de Sousa Bezerra 3

Guilhermina Rego 4

Rui Nunes 5

\section{Abstract}

Objectives: to describe the socio-demographic, behavioral, clinical and anatomical-pathological characteristics and the type of abortion in adolescents as a way of discussing the subject from a bioethical perspective

Methods: a structured questionnaire was applied to 201 adolescent girls receiving treatment for incomplete abortion and being subjected to uterine curretage, at a public maternity unit in the Northeast region of Brazil.

Results: the mean age was 16.1 years; most girls had a stable partner, were of mixed race, and were not accustomed to using condoms during sexual intercourse. The mean age for initiation of sexual activity was 15 years. Most had not planned the pregnancy but wanted to get pregnant. The mean gestational age of the fetus was 13.2 weeks. With regard to the type of abortion, $1.99 \%$ were spontaneous and $81.59 \%$ were certainly provoked, according to data obtained using the World Health Organization classification. Fetal and maternal tissue were $88.56 \%$ and $11.44 \%$, respectively. Of the abortions that were certainly provoked, there was one case of the use of a hydatidiform mole.

Conclusions: it is recommended that strategic family planning programs be urgently introduced and that anatomical-pathological tests be carried out on the material resulting from an abortion. Proactive bioethical reflection seems to be the tool for providing minimal guidelines for the protection and care of adolescents and for assisting health professionals.

Key words Abortion, induced, Bioethics, Epidemiology, Adolescent
1 Programa de Doutoramento em Bioética. Faculdade de Medicina. Universidade do Porto. Alameda Prof. Hernâni Monteiro, 4200319. Porto, Portugal. E-mail: jhbchaves@uol.com.br

2 Centro Universitário São Camilo. São Paulo, SP, Brasil.

3 Universidade Federal de Alagoas. Maceió, AL, Brasil.

4,5 Faculdade de Medicina. Universidade do Porto. Porto, Portugal.

\section{Resumo}

Objetivos: descrever características sóciodemográficos, comportamentais, clínicos, analise anatomopatológica, e o tipo de abortamento em adolescentes, de modo a discuti-los bioeticamente.

Métodos: aplicou-se questionário estruturado no atendimento a 201 adolescentes com abortamento incompleto submetidas à curetagem uterina, em uma maternidade pública no nordeste do Brasil.

Resultados: idade média de 16,1 anos; parceiro estável; mulatas; não usavam preservativos nas relações sexuais; média de idade de início de atividade sexual de 15 anos; não planejaram a gestação; desejavam a gravidez; idade gestacional média de 13,2 semanas. O desfecho da gravidez, quanto ao tipo de abortamento $1,99 \%$ abortamento espontâneo e $81,59 \%$ certamente provocados, dados obtido através da classificação da Organização Mundial da Saúde. Tecidos embrionários e maternos no anatomopatológico $88,56 \%$ e $11,44 \%$, respectivamente. Entre os abortamentos certamente provocados, um caso de mola hidatiforme.

Conclusões: recomenda-se urgência nos programas estratégicos de planejamento familiar; realização do anatomopatológico no material proveniente de aborto; a bioética refletindo pró-ativamente se apresenta como instrumento para diretrizes mínimas de proteção e assistência a adolescente, $e$ auxilio ao profissional de saúde.

Palavras-chave Aborto provocado, Bioética, Epidemiologia, Adolescente 


\section{Introdução}

Ao longo do século XIX, a adolescência passou a ser reconhecida como período crítico da existência humana. ${ }^{1}$ Segundo a Organização Mundial da Saúde, a adolescência vai dos 10 aos 20 anos incompletos, enquanto que, para o Estatuto da Criança e do Adolescente no Brasil, dos 12 aos 18 anos. ${ }^{2}$ Assim, não há consenso quanto à idade exata que no adolescente determina um grau de desenvolvimento ideal e completo para o exercício de suas competências. ${ }^{1}$

Entretanto para o Código Civil Brasileiro em seu art. 5": "a menoridade cessa aos dezoito anos completos, quando a pessoa fica habilitada à prática de todos os atos da vida civil, caso contrário para a validade dos seus atos, será preciso que estejam representados por seu pai, sua mãe ou por tutor". 3 Esta fase da vida apresenta-se, frequentemente, vinculada à vulnerabilidade e ao risco, inerentes às mudanças e transformações que a caracterizam. ${ }^{4}$

A questão do aborto é fonte de reflexões desde os primórdios da civilização e demanda diligências para a tentativa de seu enquadramento social ao longo da história do pensamento humano.1,4 Por ser o abortamento provocado considerado crime em alguns países, como é o caso do Brasil, 3 é preciso que se discutam as razões que levam as adolescentes a abortar e as consequências dessa decisão. 1

Apesar dos esforços parcialmente bem sucedidos de reduzir o número de abortos provocados no mundo 5 como também no Brasil,6 as estimativas não têm mudado significativamente. Envolto em tantos números alarmantes, a prática do abortamento suscita uma questão de saúde pública.7,8

Somam-se a isso diferenças regionais importantes: no Brasil a curetagem pós-aborto tem sido sistematicamente um dos procedimentos obstétricos mais realizados nas unidades de internação na rede pública de serviços de saúde. ${ }^{7}$ Destaca-se uma menor ocorrência de eventos infecciosos e hemorrágicos, em sua maioria atribuídos ao uso do misoprostol. ${ }^{8}$

Em que pese o fato de que a morbimortalidade materna representa apenas parte do problema, constituindo sua face mais dramática, os dados referentes à hospitalização por abortamento provocado confirmam a freqüência da realização desse procedimento como método de por fim a uma gravidez não desejada. 1,4,7,8

Sendo assim, o aborto é uma das questões conflitantes no debate bioético, porque sua essência encontra-se nos dilemas morais, onde não existem soluções imediatas nem tampouco consenso na busca de soluções. 9
A bioética tem como desafio argumentar num contexto de multiplicidade de vozes éticas. O mundo hoje está constituído por "amigos" e "estranhos" morais, no dizer de Engelhardt, 10 o que torna difícil a busca de autoridade moral tendo como base um único conteúdo.

Portanto, a bioética tem como característica primordial o estudo das problemáticas que afetam a saúde das pessoas incorporadas ao seu meio, viabilizando condições para solucioná-las.9,10 Desta forma para a abordagem de conflitos morais e dilemas éticos na saúde, a bioética se sustenta em quatro princípios, que devem nortear as discussões, decisões, procedimentos e ações na esfera dos cuidados da saúde. São eles: beneficência, nãomaleficência, autonomia e justiça. ${ }^{11}$

Constata-se que os quatro princípios não estão sujeitos a qualquer disposição hierárquica. Se houver conflito entre eles, no sentido de aplicá-los corretamente, deve-se estabelecer como, quando e o quê determinará o predomínio de um sobre o outro. 11

O presente estudo propõe descrever as características sócio-demográficos, comportamentais, clínicos, complicações, análise anatomopatológica , e o tipo de abortamento, quanto à motivação; e analisar a luz da bioética a assistência ao abortamento provocado em adolescentes que foram submetidas a curetagem uterina, em uma maternidade pública no Nordeste do Brasil.

\section{Métodos}

No período de março de 2008 a abril de 2009 , foi realizado um estudo descritivo com 201 adolescentes com diagnóstico de abortamento incompleto e que foram submetidas à curetagem uterina em hospital conveniado com o Sistema Único de Saúde em Maceió, Alagoas, Brasil.

A coleta de informações foi obtida, utilizando-se questionário com perguntas sobre, condições sóciodemográficas (idade, estado civil, etnia); comportamentos (uso de álcool e de fumo, início da atividade sexual, métodos anticoncepcionais, gravidez planejada, gravidez desejada); aspectos clínicos (idade gestacional, número de gestações, número de abortos); dados do procedimento de curetagem uterina (perfuração uterina, transfusão sanguínea); analise anatomopatológica do material proveniente da curetagem uterina.

Para classificar o tipo de abortamento, quanto à motivação aplicou-se uma lista de verificação aos questionários com roteiro pré-estabelecidos, e como critérios para identificação dos abortamentos provocados preconizou-se, conforme a Organização 
Mundial da Saúde, 12 como: certamente provocado, aquela que admitiu ter provocado o aborto ou quando foram encontrados laceração cervical e/ou corpo estranho na vagina ou no útero; provavelmente provocado, não admitiu ter provocado o aborto, mas referiu gravidez não planejada e foram encontrados sinais de sepsis ou peritonite; possivelmente provocado, quando somente uma das duas condições listadas anteriormente esteve presente.

Antes do início da entrevista, cada adolescente era informada sobre o objetivo do estudo e convidada a assinar o termo de consentimento livre e esclarecido para sua participação. As entrevistas foram realizadas em ambiente privado com acompanhamento do responsável legal.

Os princípios bioéticos, 11 foram os recursos utilizados para análise e compreensão de situações de conflito, sempre que estes se apresentavam, e ponderando as consequências das condutas.

$\mathrm{Na}$ análise dos dados aplicou-se o teste quiquadrado de associação (com correção de Yates) para tabelas $2 \times 2$. Foram considerados estatisticamente significativos os valores de $p<0,05$. O software Epi-Info versão $6.04 \mathrm{~d}$ foi utilizado para cálculo de frequências e tabelas.

Esta pesquisa foi realizada seguindo as normas para pesquisas envolvendo seres humanos, estabelecidas pela Resolução 196/96 do Conselho Nacional de Saúde, seguindo os princípios éticos da Declaração de Helsinki e após aprovação pelo Comitê de Ética em pesquisa da Universidade
Federal de Alagoas (UFAL) (Processo $\left.\mathrm{n}^{\circ} 010679 / 2008-51\right)$.

\section{Resultados}

Identificou-se nas 201 adolescentes com abortamento incompleto submetidas a curetagem uterina, que $98,0 \%$ tiveram suas gestações interrompidas voluntariamente, sendo considerados como certamente provocado $81,5 \%$, provavelmente provocado $9,9 \%$ e possivelmente provocado $6,4 \%$. A maioria das adolescentes tinha idade entre 15 e 19 anos. A idade mais frequente em que ocorreu o aborto pela primeira vez foi aos 16 anos.

Conforme mostram os dados da Tabela 1, considerando a étnia, a maioria $(60,2 \%)$ das adolescentes grávidas tinha cor parda (mulata). Com relação ao estado civil, aquelas com parceiro estável estão relacionadas em maior percentual com abortamento certamente provocado $(69,5 \%)$. Os abortamentos certamente provocados apresentam valores acima do dobro do percentual quanto a não estar com parceiro. Nas adolescentes sem parceiro, foi mais prevalente o tipo de abortamento provavelmente provocado $(70,0 \%)$. Quanto ao uso de álcool e fumo, a maioria, em todas as categorias do abortamento, não fazia uso de álcool $(88,5 \%)$ ou de fumo (83,0\%). Não houve significância estatística quando relacionadas as variáveis acima com o tipo de abortamento.

Tabela 1

\begin{tabular}{|c|c|c|c|c|c|c|c|c|c|c|}
\hline \multirow[t]{3}{*}{ Variáveis } & \multicolumn{8}{|c|}{ Tipos de abortamento } & \multicolumn{2}{|c|}{ Total } \\
\hline & \multicolumn{2}{|c|}{$\begin{array}{l}\text { Certamente } \\
\text { provocado }\end{array}$} & \multicolumn{2}{|c|}{$\begin{array}{c}\text { Provavelmente } \\
\text { provocado }\end{array}$} & \multicolumn{2}{|c|}{$\begin{array}{c}\text { Possivelmente } \\
\text { provocado }\end{array}$} & \multicolumn{2}{|c|}{ Espontâneo } & & \\
\hline & $\mathrm{n}$ & $\%$ & $\mathrm{n}$ & $\%$ & $\mathrm{n}$ & $\%$ & $\mathrm{n}$ & $\%$ & $\mathrm{n}$ & $\%$ \\
\hline \multicolumn{11}{|l|}{ Étnia } \\
\hline Branca & 53 & 32,3 & 11 & 55,0 & 5 & 38,4 & 3 & 75,0 & 72 & 35,8 \\
\hline Parda & 103 & 62,8 & 9 & 45,0 & 8 & 61,5 & 1 & 25,0 & 121 & 60,2 \\
\hline Negra & 8 & 4,8 & 0 & 0,0 & 0 & 0,0 & 0 & 0,0 & 8 & 3,9 \\
\hline \multicolumn{11}{|l|}{ Estado civil } \\
\hline Sem parceiro & 50 & 30,4 & 14 & 70,0 & 6 & 46,1 & 2 & 50,0 & 72 & 35,8 \\
\hline Com parceiro & 114 & 69,5 & 6 & 30,0 & 7 & 53,8 & 2 & 50,0 & 129 & 64,1 \\
\hline \multicolumn{11}{|l|}{ Álcool } \\
\hline Sim & 20 & 12,2 & 0 & 0,0 & 3 & 23,0 & 0 & 0,0 & 23 & 11,4 \\
\hline Não & 144 & 87,8 & 20 & 100,0 & 10 & 76,9 & 4 & 100,0 & 178 & 88,5 \\
\hline \multicolumn{11}{|l|}{ Fumo } \\
\hline Sim & 30 & 18,2 & 2 & 10,0 & 2 & 15,3 & 0 & 0,0 & 34 & 16,9 \\
\hline Não & 134 & 81,7 & 18 & 90,0 & 11 & 84,6 & 4 & 100,0 & 167 & 83,0 \\
\hline Total & 164 & 81,5 & 20 & 9,9 & 13 & 6,4 & 4 & 1,9 & 201 & 100,0 \\
\hline
\end{tabular}


A distribuição das adolescentes grávidas em relação ao comportamento sexual encontram-se na Tabela 2. Cerca de 59,2\% haviam iniciado a atividade sexual na faixa etária dos 15 aos 19 anos, nos casos de abortamentos espontâneos, a coitarca, aconteceu igualmente na mesma faixa etária. A média de idade de início de atividade sexual foi de 15 anos $(\mathrm{DP}=1,5)$, variando de 10 a 19 anos. Quanto ao número de parceiros, $57,2 \%$ referiram ter um só parceiro sexual, enquanto que $42,7 \%$ tiveram mais de dois parceiros. Em relação ao conhecimento sobre a contracepção revelado espontaneamente, 83,6 e $91,2 \%$ informaram o anticoncepcional oral e o condom, respectivamente, como os mais os que mais ouviram falar. Quanto à contracepção pelas adolescentes previamente a essa gravidez, observou-se que nenhuma das avaliadas citou uso de preservativo nas relações sexuais. Setenta por cento $(70,1 \%)$ delas não usavam método contraceptivo no mês da gestação, enquanto $(29,8 \%)$ referiram uso de algum

Tabela 2

Distribuição de adolescentes grávidas, segundo comportamento sexual, método contraceptivo e a intenção da gestação. Maceió, AL, 2008.

\begin{tabular}{|c|c|c|c|c|c|c|c|c|c|c|c|}
\hline \multirow[t]{3}{*}{ Variáveis } & \multicolumn{10}{|c|}{ Tipos de abortamento } & \multirow[t]{3}{*}{$p^{*}$} \\
\hline & \multicolumn{2}{|c|}{$\begin{array}{l}\text { Certamente } \\
\text { provocado }\end{array}$} & \multicolumn{2}{|c|}{$\begin{array}{c}\text { Provavelmente } \\
\text { provocado }\end{array}$} & \multicolumn{2}{|c|}{$\begin{array}{c}\text { Possivelmente } \\
\text { provocado }\end{array}$} & \multicolumn{2}{|c|}{ Espontâneo } & \multicolumn{2}{|c|}{ Total } & \\
\hline & $\mathrm{n}$ & $\%$ & $\mathrm{n}$ & $\%$ & $\mathrm{n}$ & $\%$ & $\mathrm{n}$ & $\%$ & $n$ & $\%$ & \\
\hline \multicolumn{12}{|l|}{ Coitarca (anos) } \\
\hline $10-14$ & 61 & 37,2 & 10 & 50,0 & 9 & 69,2 & 2 & 50,0 & 82 & 40,8 & ns \\
\hline $15-19$ & 103 & 62,8 & 10 & 50,0 & 4 & 30,7 & 2 & 50,0 & 119 & 59,2 & \\
\hline \multicolumn{12}{|l|}{$\mathrm{N}^{\circ}$ de parceiros } \\
\hline 1 & 95 & 57,9 & 11 & 55,0 & 7 & 53,8 & 2 & 50,0 & 115 & 57,2 & ns \\
\hline 2 ou 3 & 56 & 34,1 & 8 & 40,0 & 6 & 43,1 & 2 & 50,0 & 72 & 35,8 & \\
\hline 4 ou mais & 13 & 7,9 & 1 & 5,0 & 0 & 0,0 & 0 & 0,0 & 14 & 6,9 & \\
\hline \multicolumn{12}{|l|}{ Anticoncepcional } \\
\hline Nenhum & 121 & 73,7 & 12 & 60,0 & 6 & 46,1 & 2 & 50,0 & 141 & 70,1 & ns \\
\hline Oral & 3 & 1,8 & 0 & 0,0 & 1 & 7,6 & 0 & 0,0 & 4 & 1,9 & \\
\hline Injeção mensal & 1 & 0,6 & 0 & 0,0 & 0 & 0,0 & 0 & 0,0 & 1 & 0,5 & \\
\hline $\begin{array}{l}\text { Dispositivo intra } \\
\text { uterino }\end{array}$ & 2 & 1,2 & 0 & 0,0 & 0 & 0,0 & 0 & 0,0 & 2 & 1,0 & \\
\hline Injeção trimestral & 22 & 13,4 & 4 & 20,0 & 3 & 23,0 & 1 & 25,0 & 30 & 14,9 & \\
\hline $\begin{array}{l}\text { Coito } \\
\text { interrompido }\end{array}$ & 15 & 9,1 & 4 & 20,0 & 3 & 23,0 & 1 & 25,0 & 23 & 11,4 & \\
\hline Condon & 0 & 0,0 & 0 & 0,0 & 0 & 0,0 & 0 & 0,0 & 0 & 0,0 & \\
\hline \multicolumn{12}{|l|}{ Gravidez planejada } \\
\hline Sim & 68 & 41,4 & 4 & 20,0 & 1 & 7,6 & 0 & 0,0 & 73 & 36,3 & ns \\
\hline Não & 96 & 58,5 & 16 & 80,0 & 12 & 92,3 & 4 & 100,0 & 128 & 63,6 & \\
\hline \multicolumn{12}{|l|}{ Gravidez desejada } \\
\hline Sim & 140 & 85,3 & 4 & 20,0 & 1 & 7,6 & 2 & 50,0 & 147 & 73,1 & ns \\
\hline Não & 24 & 14,6 & 16 & 80,0 & 12 & 92,3 & 2 & 50,0 & 54 & 26,8 & \\
\hline \multicolumn{12}{|l|}{ Gravidez planejada } \\
\hline \multicolumn{12}{|l|}{ e desejada } \\
\hline Sim & - & - & - & - & - & - & - & - & 195 & 97,2 & \\
\hline Não & - & - & - & - & - & - & - & - & 6 & 2,8 & \\
\hline $\begin{array}{l}\text { Gravidez desejada } \\
\text { mas não planejada }\end{array}$ & & & & & & & & & & & $<0,001$ \\
\hline Sim & - & - & - & - & - & - & - & - & 119 & 59,3 & \\
\hline Não & - & - & - & - & - & - & - & - & 82 & 40,7 & \\
\hline Total & 164 & 81,5 & 20 & 9,9 & 13 & 6,4 & 4 & 1,9 & 201 & 100,0 & \\
\hline
\end{tabular}

${ }^{*} p$, ns=não significante (teste $\left.\chi^{2}\right)$. 
método anticoncepcional antes de ficarem grávidas. Dentre os métodos, o mais utilizado foi o anticoncepcional injetável sendo $0,5 \%$ mensal e $14,9 \%$ trimestral. Dentre as que referiram ter provocado o abortamento ou com quadro em que a interrupção foi supostamente provocada, $63,6 \%$ não haviam planejado a gravidez e $26,8 \%$ não a haviam desejado.

A distribuição das adolescentes que abortaram em comparação àquelas que desejaram e planejaram a gravidez encontram-se na Tabela 2. Comparando a amostra total dos casos, a proporção daquelas que desejaram e planejaram $195(97,2 \%)$ foi maior do que aquelas que desejaram, mas não planejaram 119 $(59,3 \%)(p<0,001)$. Sendo essa diferença estatisticamente significante, qui-quadrado corrigido por Yates de $34,42(p<0,001)$.

Considerou-se a idade gestacional em semanas calculada a partir do primeiro dia da data da última menstruação e confirmada pela ultra-sonografia precoce quando disponível. A idade gestacional média foi de 13,2 semanas, com variação de dez a dezessete semanas de gestação.

Verificou-se que em 164 adolescentes de abortamento certamente provocado, a idade gestacional em que ocorreu a perda gestacional, $85,9 \%$ das vezes, foi antes de 15 semanas, isto é, na fase de abortamentos tardios.

Com relação ao número de gestações e à paridade, entre as adolescentes com abortamento provocado, o maior percentual $(52,2 \%)$ era daquelas na primeira gestação. Enquanto, $41,2 \%$ eram primigestas, $26,8 \%$ dois partos e $17,4 \%$ já tinham três ou mais partos.

Nesta amostra, o aborto provocado foi realizado apenas uma vez em $(10,9 \%)$ das adolescentes. No entanto, $86,5 \%$ delas afirmaram nunca tê-lo praticado, havendo repetição de duas vezes por $(2,4 \%)$ das adolescentes e acima de três vezes por nenhuma. Os abortamentos espontâneo, $100,0 \%$ referiam nunca haver abortado.

A Tabela 3 apresenta os métodos utilizados para indução do abortamento. Entre as 164 adolescentes consideradas como abortamento certamente provocado, $77,4 \%$ assumiram ter feito uso do misoprostol como método para a indução do aborto, $2,4 \%$ referiram outros métodos, destes apenas um caso foi declarado o uso de sonda intra-uterina. Nos demais casos $(20,1 \%)$ não assumiram, mas apresentou sinais de manobras abortivas ao exame do genital (lesões de vulva, vagina ou colo uterino)

A Tabela 4 mostra a distribuição das adolescentes grávidas, segundo complicações decorrentes do abortamento.

Entre os casos de adolescentes com perfuração uterina, $(1,4 \%)$, em 1 , o tipo de abortamento foi certamente provocado, não havendo caso de perfuração no abortamento espontâneo.

A transfusão sanguínea foi realizada em $(4,4 \%)$. Destes, em $88,8 \%$, o abortamento foi classificado como certamente provocado, e houve $(11,1 \%)$ abortamento provavelmente provocado. Não foi registrado nenhum caso de transfusão nos abortamentos espontâneos.

Conforme mostram os dados da Tabela 5, a análise anatomopatológica do material oriundo de curetagem da cavidade uterina, foi considerado em dois grupos, tecidos embrionários $(88,5 \%)$ e tecidos maternos $(11,4 \%)$. Destes, $82,6 \%$ foi considerado abortamento certamente provocado. Entre os casos que o exame anatomopatológico evidenciou tecido embrionário houve registro de um caso de mola hidatiforme completa, incluído no grupo dos abortamentos certamente provocado $(81,4 \%)$.

Tabela 3

Distribuição de adolescentes com abortamentos certamente provocado, segundo método utilizado. Maceió, AL, 2008.

\begin{tabular}{lrcc}
\hline Métodos & N & $\%$ & $\boldsymbol{p}^{*}$ \\
\hline Misoprostol & 127 & 77,4 & $\mathrm{~ns}$ \\
Chás & 1 & 0,6 & \\
Sonda & 1 & 0,6 & \\
Permanganato de potássio & 2 & 1,2 & \\
Sinais de manipulação & 33 & 100,0 & \\
Total & 164 & 20,1 & \\
\hline
\end{tabular}

${ }^{*} p, \mathrm{~ns}=$ não significante (teste $\chi^{2}$ ). 
Distribuição de adolescentes grávidas, segundo complicações decorrentes do abortamento. Maceió, AL, 2008.

\begin{tabular}{|c|c|c|c|c|c|c|c|c|c|c|c|}
\hline \multirow{4}{*}{$\begin{array}{l}\text { Tipos de } \\
\text { abortamento }\end{array}$} & \multicolumn{8}{|c|}{ Riscos do procedimento } & \multicolumn{2}{|c|}{ Total } & \multirow[t]{4}{*}{$p^{*}$} \\
\hline & \multicolumn{4}{|c|}{ Perfuração uterina } & \multicolumn{4}{|c|}{ Transfusão de sangue } & & & \\
\hline & \multicolumn{2}{|c|}{ Sim } & \multicolumn{2}{|c|}{ Não } & \multicolumn{2}{|c|}{$\operatorname{Sim}$} & \multicolumn{2}{|c|}{ Não } & \multirow[b]{2}{*}{$\mathrm{n}$} & \multirow[b]{2}{*}{$\%$} & \\
\hline & $\mathrm{n}$ & $\%$ & $\mathrm{n}$ & $\%$ & $\mathrm{n}$ & $\%$ & $\mathrm{n}$ & $\%$ & & & \\
\hline $\begin{array}{l}\text { Certamente } \\
\text { provocado }\end{array}$ & 1 & 33,3 & 163 & 82,3 & 8 & 88,8 & 156 & 81,2 & 164 & 81,5 & ns \\
\hline $\begin{array}{l}\text { Provavelmente } \\
\text { provocado }\end{array}$ & 2 & 66,6 & 18 & 9,0 & 1 & 11,1 & 19 & 9,9 & 20 & 9,9 & \\
\hline $\begin{array}{l}\text { Possivelmente } \\
\text { provocado }\end{array}$ & 0 & 0,0 & 13 & 6,5 & 0 & 0,0 & 13 & 6,7 & 13 & 6,4 & \\
\hline Espontâneo & 0 & 0,0 & 4 & 2,0 & 0 & 0,0 & 4 & 2,0 & 4 & 1,9 & \\
\hline Total & 3 & 1,4 & 198 & 98,5 & 9 & 4,4 & 192 & 95,5 & 201 & 100,0 & \\
\hline
\end{tabular}

${ }^{*} p$, ns=não significante (teste $\chi^{2}$ ).

Tabela 5

Distribuição de adolescentes, segundo anatomopatológico e o tipo de abortamento. Maceió, AL, 2008.

\begin{tabular}{|c|c|c|c|c|c|c|c|}
\hline \multirow{3}{*}{$\begin{array}{l}\text { Tipos de } \\
\text { abortamento }\end{array}$} & \multicolumn{4}{|c|}{ Exame anatomopatológico } & \multicolumn{2}{|c|}{ Total } & \multirow[t]{3}{*}{$p^{*}$} \\
\hline & \multicolumn{2}{|c|}{$\begin{array}{c}\text { Tecidos } \\
\text { embrionários }\end{array}$} & \multicolumn{2}{|c|}{$\begin{array}{l}\text { Tecidos } \\
\text { maternos }\end{array}$} & \multirow[b]{2}{*}{$\mathrm{n}$} & \multirow[b]{2}{*}{$\%$} & \\
\hline & $\mathrm{n}$ & $\%$ & $\mathrm{n}$ & $\%$ & & & \\
\hline Certamente provocado & 145 & 81,4 & 19 & 82,6 & 164 & 81,5 & ns \\
\hline Provavelmente provocado & 18 & 10,1 & 2 & 8,7 & 20 & 9,9 & \\
\hline Possivelmente provocado & 11 & 6,1 & 2 & 8,7 & 13 & 6,4 & \\
\hline Espontâneo & 4 & 2,2 & 0 & 0,0 & 4 & 1,9 & \\
\hline Total & 178 & 88,5 & 23 & 11,4 & 201 & 100,0 & \\
\hline
\end{tabular}

${ }^{*} p$, ns=não significante (teste $\chi^{2}$ ).

\section{Discussão}

Discutir a temática do abortamento provocado pressupõe a realização de um exercício reflexivo. $\mathrm{Na}$ perspectiva de Nunes, ${ }^{13}$ a formulação de um estatuto quanto à vida intra-uterina, nas suas diferentes fases de desenvolvimento, só assim se legitima a discussão acerca da interrupção da gravidez.

No presente estudo, o abortamento foi certamente provocado em $81,5 \%$ das adolescentes. Outra forma possível de análise desta atitude por parte das adolescentes, e principalmente tratando-se de um país latino americano, onde existe uma grande dife- rença sócio-econômico-cultural tendem a ser mais submissos, não estando acostumados a exercerem sua autonomia, aceitam sem questionamentos a falha na assistência a saúde reprodutiva ofertada, sem responsabilizarem as políticas públicas. ${ }^{14}$

No domínio da bioética, o principal dilema concerne ao conflito que se estabelece entre o respeito pela autonomia individual e o valor da vida humana intra-uterina. A atribuição de um estatuto moral à vida humana intra-uterina apresenta como principal argumento uma perspectiva biológica do desenvolvimento humano, evidenciando os marcos do desenvolvimento intra-uterino que lhe conferem 
uma maior individuação e valoração ao nível das sucessivas semanas de gestação.

No entanto, a discussão acerca do estatuto moral do embrião humano, visando o reconhecimento do seu valor não como uma pessoa humana no sentido filosófico do termo, pretende identificar a partir de quando o respeito pela vida humana lhe deve ser outorgado. Assim, as asserções mais comuns a este respeito apresentam duas correntes. Uma indica que a vida humana existe desde o momento da concepção e outra afirma que o estatuto moral do embrião humano deve ser atribuído a partir da constituição do sulco primitivo no desenvolvimento embrionário. 13

Com relação à idade da adolescente nossos resultados mostraram que $88,0 \%$ estavam na faixa de 15 a 19 anos, sendo que a média de idade foi 16 anos. A maioria era de cor parda (mulata) $(60,2 \%)$ e $69,5 \%$ delas tinham parceiro estável. Semelhantemente ao observado por outros autores 6 em pesquisas realizadas em hospitais brasileiros, o panorama da assistência continua o mesmo, independente da região onde se pesquise o tema.

Em relação à magnitude do problema, Vieira et al.15 chama a atenção para o fenômeno nesta faixa etária e sugere haver uma procura do aborto como meio de evitar filhos, não havendo a etapa preventiva correta do uso de métodos contraceptivos.

Outra questão frequente neste domínio é a colocada a propósito de determinadas formas de contracepção. Nomeadamente métodos impeditivos de nidação como o dispositivo intra-uterino (DIU) ou a contracepção de emergência, constituem-se em formas de abortamento. 16

A resposta a esta questão remete novamente para a diferenciação do embrião no seu estatuto moral. 13 Para os que consideram estes métodos abortivos apresentam uma concepção relativa ao estatuto moral do embrião humano no sentido em que este deve ser valorizado a partir do momento da concepção. Por outro lado, ao considerar-se o valor da vida humana a partir do momento em que a nidação se completa, por volta do $14^{\circ}$ dia de gestação, estes métodos não poderão ser considerados abortivos, mas sim anticoncepcionais. ${ }^{17}$

No presente estudo a maioria das adolescentes tinha feito sua iniciação sexual entre 15 e 19 anos, com media de idade de 15 anos, encontrava-se na primeira gestação e com idade gestacional abaixo de 15 semanas, não estava utilizando método contraceptivo $70,1 \%$, e nenhuma referiu o uso de condon. Farias Júnior et al.,18 observou que a primeira relação sexual entre adolescentes brasileiras está ocorrendo cada vez mais cedo.
Vale destaque as pesquisas, $19,20,21$ em uma avaliação do ponto de vista social a prática do abortamento na adolescência deve ser analisado em uma perspectiva mais ampla, à luz das mudanças ocorridas nas sociedades ocidentais, com a massificação da escolarização feminina, a disseminação dos valores do feminismo e o recurso a contraceptivos eficazes.

Por outro ângulo, o raciocínio acerca dos princípios de autonomia e de beneficência torna-se difícil, por se envolverem na reflexão duas entidades distintas, a gestante e o nascituro. Neste sentido, Nunes 13 considera que nunca se saberia quem seria beneficiado com determinada ação. Há ainda a questão da autonomia, difícil de definir no seu exercício por parte do nascituro.

Dentre as adolescentes com interrupção da gravidez supostamente provocada, $63,6 \%$ não haviam planejado a gravidez e $73,1 \%$ não a haviam desejado. Cerca de $89,1 \%$ destes, foi relacionado ao uso do misoprostol. Desta forma, para saber o que é o melhor para cada uma das adolescentes que busca o abortamento provocado como terapêutica a uma gravidez não desejada é preciso que se estabeleça um relacionamento interpessoal de confiança mútua e que o médico esteja atento aos limites de sua atuação, uma vez que poderá estar ferindo o princípio da autonomia. 10

A proposta da International Federation of Gynecology and Obstetrics (FIGO), 22 decorre do direito da mulher à sua autonomia, combinado com a necessidade de prevenir o abortamento realizado de modo inseguro e clandestino. No entanto, considera que os governos devem esforçar-se em promover os direitos, os graus de protagonismo social e saúde da mulher, devem tentar prevenir a gravidez indesejada através da educação, do aconselhamento e da disponibilização da informação adequada que permita uma decisão reprodutiva adequada, recorrendo ao planejamento familiar e não ao abortamento que não se constitui num método contraceptivo. 23,24

Em todos os casos selecionados para o nosso estudo, o tratamento de escolha foi a curetagem uterina para remoção dos restos placentários. Foi observado como complicação, perfuração uterina em três casos $(1,4 \%)$ e transfusão sanguínea em oito casos, todos entre os abortamentos certamente provocados. No exame anatomopatológico, foi encontrado material representativo de restos embrionários em apenas $88,5 \%$ dos casos. Constata-se, portanto, que em $11,4 \%$ das adolescentes, o abortamento já tinha se completado espontaneamente, antes da curetagem uterina. 
Sendo assim, o achado de um caso de mola hidatiforme entre as 201 adolescentes grávidas, têm relevância, por se tratar de uma doença com potencial de transformação e curável em quase $100 \%$ dos casos. Este fato, aliado aos relatos da literatura 25 faz com que se reforce ainda mais a necessidade do exame anatomopatológico em todo material de abortamento, sobretudo naqueles com diagnóstico de gravidez precoce inviável. Não existe ainda no Brasil, por parte do Ministério da Saúde, ${ }^{8}$ recomendação para a realização do exame anatomopatológico dos restos ovulares.

No âmbito do princípio da beneficência é considerado pertinente o acesso a estes cuidados de saúde como expressão do direito de autodeterminação em matéria de saúde das mulheres afetados por esta problemática. Portanto, à luz deste princípio, Sgreccia 16 considera que se devem empenhar todos os mecanismos capazes de evitar danos a saúde da população. De igual forma, e numa perspectiva de justiça distributiva, os mesmos devem ter igual acesso às oportunidades de diagnóstico e tratamento.

O princípio da não-maleficência, no âmbito da ética médica, encontra-se intimamente associado à máxima primum non nocere, 11 que pressupõe, no âmbito da prestação dos cuidados de saúde, primeiramente não causar dano ao paciente. Este princípio impele a não fazer mal intencionalmente, relacionando-se assim com a máxima do Juramento de Hipócrates que considera que, pelo menos, não se deve causar mal.13

Assim como transparece do Juramento de Hipócrates, algumas teorias éticas consideram existir similaridade entre os princípios de não-maleficência e beneficência.11 No entanto à luz desta teoria considera-se a sua diferenciação possível do ponto de vista conceptual. Desta forma, subjacente ao princípio da não-maleficência considera-se que não se deve causar dano ou mal.

Doutro modo, o princípio da beneficência indica que se deve prevenir o dano e o mal, deve-se evitar causar dano ou mal e se deve fazer ou promover o bem. Enquanto o princípio da beneficência implica ajudar ativamente o paciente, o da não-maleficência pressupõe apenas a abstenção da realização de ações que intencionalmente possam causar dano.

\section{Referências}

1. Saito MI, Leal MM. Adolescência e contracepção de emergência: Fórum 2005. Rev Paul Pediatr. 2007; 25: 180-

\section{Considerações finais}

Tendo em vista a presente discussão, infere-se ser recomendável que o médico evite a prática paternalista de assumir, sozinho, a escolha da adolescente pela interrupção da gravidez, mas que tenha mecanismos subsidiários para que possa exercer sua profissão sem que tenha de desrespeitar promoção da autonomia da gestante adolescente, ao proteger o seu direito de escolha.

Deste modo, através de uma educação para a saúde realizada de modo longitudinal, estar-se-ia a contribuir para uma tomada de decisão livre e informada de cada indivíduo sobre si e sobre o seu corpo. Pelo reconhecimento de que o abortamento provocado não é, nem deve ser encarado como um método anticoncepcional, a educação para a saúde deve ser exercida de modo que as mulheres previnam e minimizem o seu recurso a esta prática. 16

Assim, considerando-se o referencial apresentado e os dados descritos, pode-se considerar que é dever do Estado garantir o acesso a planejamento familiar, respeitando sua liberdade de escolha e subsidiando os meios para que a mesma se baseie em uma prática de fato autônoma, salvo recomendações médicas em contrário. Nesse sentido, cumpre salientar que tal proposta estaria respaldada não apenas no referencial principialista, 11 focado na reflexão sobre os critérios definidores da autonomia pessoal, mas também nas diretrizes apontadas pelas bioéticas dos países de língua portuguesa. 26

Para tanto, faz-se necessário reconhecer, conforme o pensamento, que reside no principialismo11 o mérito de ter sido o primeiro referencial teórico capaz de colocar de forma sistemática, na arena de discussões acadêmicas e para o público em geral, a necessidade de se proteger as pessoas vulneráveis. 27

Nesse contexto, a bioética propõe ações mínimas no sentido de envolvimento de profissionais das áreas da saúde e educação, a fim de promover a saúde sexual e oferecer assistência imediata às mulheres acometidas pelo abortamento, principalmente no grupo das adolescentes, no qual a prevenção da gravidez não planejada poderia evitar a ocorrência do abortamento e consequentemente uma melhor qualidade e valorização da vida.
2. Brasil. Estatuto da Criança e do Adolescente. Lei $\mathrm{n}^{0}$ 8.069/1990 [acessado em 12 mar 2010]. Disponível em: www.planalto.gov.br/ccivil 03/Leis/L8069.htm 
3. Fiuza R. Novo código civil comentado. São Paulo: Saraiva; 2002 .

4. Hardy E, Costa RG, Rodrigues T; Moraes TM Características atuais associadas à história de aborto provocado. Rev Saúde Pública. 1994; 28: 82-5.

5. WHO (World Health Organization). Unsafe abortion: global and regional estimates of the incidence of unsafe abortion and associated mortality in 2000. 4 ed. Geneva 2004. [acesso em 26 fev 2010]. Disponível em: http://www.who.int/reproductivehealth/publications/unsafe abortion_estimates_04/estimates.pdf

6. Brasil. Datasus. Sistema de informações de saúde (SIS) 2008. [acesso em: 24 jan 2010]. Disponível em: http://tabnet.datasus.gov.br/cgi/deftohtmexe?sim/cnv/matuf .def

7. Brasil. Ministério da Saúde. Departamento de Ciência e Tecnologia. Secretaria de Ciência, Tecnologia e Insumos Estratégicos. 20 anos de pesquisas sobre aborto no Brasil Brasília, DF; 2008.

8. Brasil. Ministério da Saúde. Secretaria de Atenção à Saúde. Departamento de Ações Programáticas Estratégicas. Atenção humanizada ao abortamento: norma técnica. Brasília, DF; 2005

9. Pessini L, Barchifontaine CP. Problemas atuais de bioética 5 ed. São Paulo: Loyola; 2000.

10. Engelhardt TH. Fundamentos da bioética. Tradução José A. Ceschim. São Paulo: Loyola; 1998. p. 116-22.

11. Bauchamp TL, Childress JF. Princípios de Ética Biomédica. São Paulo: Loyola; 2002. p. 282-6.

12. World Health Organization. Protocol for hospital Based descriptive studies of mortality, morbidity related to induced abortion, WHO Project $\mathrm{n}^{\circ}$ 86.912. Task Force on Safety and Efficacy of Fertility Regulating Methods. Geneva; 1987. Revised edition of Aug. 14.

13. Nunes R. O diagnóstico pré-natal da doença genética. In: Nunes R, Melo H, coord. Genética e reprodução humana. Coimbra: Gráfica de Coimbra; 2000. p. 81-132.

14. Motta IS. A relação interpessoal entre profissionais de saúde e a mulher em abortamento incompleto: o olhar da mulher. Rev Bras Saúde Matern Infant. 2005; 5: 219-28.

15. Vieira LM, Goldberg TB, Saes SO, Dória AAB. Abortion and miscarriage in adolescence: an epidemiological study. Ciên Saúde Colet. 2007; 12: 1201-8.

Recebido em 12 de maio de 2010

Versão final apresentada em 12 de novembro de 2010

Aprovado em 1 de dezembro de 2010
16. Sgreccia E. Aborto: o ponto de vista da bioética. Estoril: Princípia Editora. 2006

17. Menezes GMS, Aquino EML, Silva OD. Induced abortion during youth: social inequalities in the outcome of the first pregnancy. Cad Saúde Pública. 2006; 22: 1431-46.

18. Farias Júnior JC, Nahas MV, Barros MVG, Loch MR, Oliveira ESA, De Bem MFL, Silva AL. Comportamentos de Risco à Saúde em adolescentes no Sul do Brasil: prevalência e fatores associados. Rev Panam Salud Pública. 2009; 25: 34-52.

19. Carvalho ML, Schor N. Reasons why sterilized women refused reversive contraceptive methods. Rev Saúde Pública. 2005; 39: 788-94

20. Schor N, Alvarenga AT. O aborto: um resgate histórico e outros dados. [acesso em 11 jan 2010]. Disponível em: http://www.fsp.usp.br/SCHOR.HTM

21. Chaves JHB, Pessini L, Bezerra AFS, Nunes R. Abortamento provocado e o uso de contraceptivos em adolescentes. Rev Bras Clin Med. 2010; 8: 94-100.

22. FIGO (International Federation of Gynecology and Obstetrics). Recommendations on ethical issues in obstetrics and gynecology by the FIGO Committee for the Study of Ethical Aspects of Human Reproduction. London: 2006. [acesso em 13 abr 2010]. Disponível em: http:www.figo.org/about/ethics

23. Souza VLC, Corrêa MSM, Souza SL, Beserra MA. O aborto entre adolescentes. Rev Latinoam Enfer. 2001; 9: 42-7.

24. Rossier C. Estimating Induced Abortion Rates: a review. Stud Fam Plann. 2003; 34: 87-102.

25. Tasci Y, Dilbaz S, Secilmis O, Dilbaz B, Ozfuttu A, Haberal A. Routine histopathologic analysis of product of conception following first-trimester spontaneous miscarriages. Gynaecol Res J Obstet. 2005; 31: 579-82.

26. Chaves JHB, Pessini L, Bezerra AFS, Nunes R. Aborto e bioética: uma discussão sempre atual. Brasília Med. 2010; 47: 87-92.

27. Garrafa V, Prado M. Mudanças na Declaração de Helsinki fundamentalismo econômico, imperialismo ético e controle social. Cad Saúde Pública. 2001; 17: 1489-96. 